normal saline solution, plus serum of a rabbit which has been inmunized to the particular red blood cells used.

Complement (a substance necessary to all immune reactions, which existed in the fresh serum of all animals) in the shape of fresh normal guinea-pig serum, was now added to Tube $x$ and allowed to stand. At the end of a half hour the contents of Tube I were added to that of Tube 2. If the serum in Tube $\mathrm{I}$ had come from a syphilitic individual, its relation to the extract of antigen was a specific one, and complement would be absorbed thereby; so that, when the contents of Tubes $r$ and 2 were joined, no hemolysis of the red blood cells in Tube 2 would take place. If the serum was not from a syphilitic, complement would not be absorbed, but would remain active to cause hemolysis in Tube 2 .

Hemolysis was observed in the test tube as a tinging of the whole field with a transparent red color. The red corpuscles had been disintegrated and the hemoglobin liberated. In the absence of hemolysis the solution of red cells remained turbulent and opaque.

The test, of course, involved numerous controls and a careful standardizing of the hemolytic serum and of the syphilitic extract.

\title{
THE TECHNIQUE OF THE WASSERMANN REACTION: ITS PRACTICAL APPLICATION WITH REFERENCE T'O DIAGNOSIS, PROGNOSIS AND TREATMENT OF NERVOUS DISEASE
}

\author{
By E. Castelli, M.D.
}

After describing in detail the technique of the Wassermann reaction, the author offered the following conclusions:

I. From the social standpoint, the serum diagnosis of syphilis represented one of the greatest achievements attained by medicine at the present time. The role played by syphilis in the life of mankind required no explanation. The highest coefficient to degeneracy and insanity was created by syphilis.

2. If we were now in a position to tell our patient that notwithstanding his previous syphilitic infection he could marry and create a healthful progeny, we would certainly have at our command a tremendous factor for benefiting a large proportion of our fellow beings.

3. If we could establish the fact that syphilis was curable, and did not hang like the sword of Damocles over a man's physical and mental future, again would medicine have triumphed.

4. From a legal standpoint, the fact that we might be able to aid either the prosecution or the defense with the knowledge that the criminal had a clain on the court's leniency by reason of a previous syphilitic infection, which had produced a derangement of his mental poise, it might become an important factor in the administration of justice.

5. The sero-diagnosis of syphilis would be a means of differential diagnosis during the pre-paralytic stage, when the general symptoms were very indefinite and generally masked by a well-defined neurasthenic syndrome. The differential diagnosis between general paralysis and neurasthenia during this period would represent the real prophylactic warning. The patient, during this pre-paralytic stage, was already dangerous to himself, his family and to society at large, and our early recognition of his condition made possible the safe-guarding of the patient. 
6. While the sero-diagnosis of syphilis in its present condition was not perfect, and owing to its complicated technique and to the difficulty of procuring the necessary ingredients it was limited to a few privileged students, yet it had the indisputable advantage of furnishing us with a rich amount of positive diagnostic data, and the speaker said he considered its adoption in the various hospitals and medical institutions not optional, but absolutely necessary.

\section{DEMONSTRATION OF WASSERMANN REACTION T'EST}

\section{By Dr. Noguchi, of the Rockefeller Institute}

After demonstrating the Wassermann reaction, Dr. Noguchi showed briefly a reaction evolved by him during some experimentation with the various albumin reactions in the spinal fluids of general paralysis and other disorders. This was obtained as follows: o.I c.c. of the spinal fluid to be tested is placed in a test-tube whose diameter is I cm. or less. To this is added 0.5 c.c. of a ro per cent. solution of butyric acid. The tube is now heated until the fluid is bubbling, and while still hot o.I c.c. of a normal (4 per cent.) solution of sodium hydrate is added. In nearly all spinal fluids an opalescence or cloud occurs, but in the spinal fluid of general paralysis the cloud soon separates into a definite flocculence which is characteristic. The flocculence usually appears in a few momentsrarely requiring more than 20 minutes.

The reaction shown by Dr. Noguchi had the advantage of being positive in a quantity of o.I c.c. or less, and of being a qualitative as well as a quantitative test. What the flocculence might mean was not known, but it might consist of some globulin fraction which was found only in syphilitic or meta-syphilitic disorders of the nervous system. That the reaction was not entirely quantitative was shown by the fact that many fluids from non-paralytic cases gave much richer clouds than those from paresis, but the clouds did not flocculate.

Dr. J. W. Moore, of the State Pathological Institute, Ward's Island, said they had tested thus far 80 cases by the Noguchi method. Fifty undoubted cases of paresis gave 48 positive results. The two negative cases did not seem peculiar in any way. Of three cases of cerebral syphilis, two gave positive reactions. Of the non-paralytic cases tested, five were alcoholic psychoses, ten dementia præcox, four epileptic psychoses, two manic-depressive cases, one paranoic state, one imbecile and one case which was diagnosed as Karsakow's delirium, but which proved at autopsy to be due to a fractured skull with extensive diffuse dural hematoma. Only one of the non-paralytic cases gave a positive reaction. This was a case, diagnosed dementia pracox, which had, however, increased knee-jerks and speech defect. Five doubtful cases gave two positive results and three negative.

In the majority of cases of paresis, the Wassermann reaction was also carried out. Four cases of general paralysis which were negative to the Wassermann test were positive to the other. Four gave the Wassermann reaction much less definitely than did the Noguchi reaction. In no case was the Wassermann test the more conclusive of the two. In two of the cerebral syphilic cases in which the Wassermann reaction was tried it gave a negative result. 